UDK 78.038 6Ruzicka

$$
\text { Gregor Pompe }
$$

Filozofska fakulteta Univerze v Ljubljani

Philosophical Faculty, University of Ljubljana

\title{
Palimpsestna struktura skladbe Tallis Petra Ruzicke ali v kolikšni meri je postmodernizem odvisen od modernizma
}

\section{Palimpsest Structure of Peter Ruzicka's Composition Tallis or to What Extent Does Postmodernism Depend upon Modernism}

Ključne besede: modernizem, postmodernizem, Peter Ruzicka, glasba 20. stoletja

IZVLEČEK

Članek skuša razložiti naravo odnosa med modernizmom in postmodernizmom, pri čemer izpostavlja tisto možnost, po kateri gre v postmodernizmu za nadaljevanje in radikalizacijo modernizma. Ta teza je ilustrirana na primeru simfoničnega dela Tallis Petra Ruzicke, ki je zasnovano kot palimpsest.
Keywords: modernism, postmodernism, Peter Ruzicka, $20^{\text {th }}$ century music

Abstract

The article attempts to explain the nature of the relationship between modernism and postmodernism, exposing the possibility of postmodernism being a continuation and radicalisation of modernism. This thesis is demonstrated by taking as an example Peter Ruzicka's symphonic work Tallis, conceived of as a palimpsest.

Pregled različnih teorij postmodernizma kaže precej nenavadno sliko - ne toliko zato, ker se avtorji o pogledih na glavne značilnosti tega obdobja močno razhajajo, temveč predvsem zato, ker ugotavljajo, da pojem sam morda sploh ni najbolj ustrezen in dovolj premišljeno izbran. Tako Brian McHale, eden izmed vodilnih teoretikov trdi, da ni »[n]ič v zvezi s tem pojmom [...] neproblematičnega, nič na njem ni popolnoma zadovoljujočega ${ }^{1}$ in pri tem še dodaja: „Nihče ne mara termina, vendar ga uporabljajo 
raje kot nekatere druge še manj zadovoljive alternative. $\aleph^{2}$ Še bolj kritičen je Niall Lucy: »Poizkusi definiranja postmodernizma so notorično nezadovoljivi. Tako zelo, da je postala v igri definiranja postmodernizma standardna poteza priznanje, da je njegovo definiranje notorično nezadovoljivo. $\aleph^{3}$ Tako situacijo je mogoče povezati s prevladujočo metodologijo raziskovanja: avtorji ne raziskujejo "postmodernizma«, temveč obdobje, ki mu na podlagi določenih značilnosti podeljujejo začasno ime "postmodernizem«. Razlogov za zmedo in nejasnosti pa je seveda še veliko več.

Kljub temu se je pojem precej hitro utrdil v vsakodnevni publicistiki, kjer so njegovi obrisi in vsebina postali še bolj izmuzljivi. V številnih časnikarskih prispevkih, ki so bili objavljeni od srede sedemdesetih let 20. stoletja naprej v ameriškem in deloma tudi evropskem tisku, se je postmodernizem pogosto izenačevalo kar z antimodernizmom; ${ }^{4}$ zdelo se je namreč, da nova smer prekinja s hermetizmom modernizma, njegovo zaprtostjo in elitistično-moralno privzdignjenostjo, kar so medijske hiše v dobi razcveta množičnih občil sprejele z odprtimi rokami. Tako je pojem čez noč postal moden; še predno bi bil natančneje določen njegov obseg, so ga široke strukture izobražencev že pričele uporabljati.

Del problematike je gotovo povezan že s samim jezikovnim ustrojem termina, saj imamo opravka s sestavljanko iz jedra ("modernizem») in predpone (»post»), kar pomeni, da je pojem močno odvisen od našega definiranja modernizma in relacije, ki jo določa predpona - izkaže se, da je na postmodernizem potrebno gledati kot na relacijski pojem in da je vsebina pojma v največji meri odvisna že od našega definiranja modernizma. Mnogo dilem okoli različnih pojmovanj postmodernizma je povezanih prav z relacijsko naravo samega pojma, ki odpira številne raznolike možnosti in soodvisnosti. Tako Janko Kos poudarja, da »analize slovenskega postmodernizma ne bo mogoče zadovoljivo izpeljati, ne da bi zajela zlasti njegovo razmerje do modernizma." Podobno je prepričana tudi velika večina muzikologov, ki se ukvarjajo s postmodernizmom. Helga de la Motte-Haber celo ne vidi osrednjega problema v predponi "post«, temveč v samem razumevanju modernizma, ki je že dovolj raznoliko, ${ }^{6}$ zato ni čudno, da je R. Feller prepričan, da »obstaja prav toliko tipov postmodernizma kot modernizma. " V prašanje, ali gre pri postmodernizmu za nadaljevanje modernističnega izročila ali njegovo popolno zanikanje - torej dilemo povezano s predpono "post « -, postane v tej luči šele sekundarnega pomena: predpona "post « je odvisna od svojega referenta - brez slednjega, kakor trdi N. Kompridis, ne pove skoraj ničesar. ${ }^{8}$

Prav tam, str. 3-4.

Niall Lucy, Postmodern Literary History: An Introduction, Oxford in Malden, Blackwell Publishers 1997 , str. 63.

Tak tipični »časnikarski" pogled je leta 1969 prinesel Leslie Fiedler, ki je v reviji Playboy objavil članek Cross the Border Close the Gap. V njem je pozitivno ocenil stapljanje elitne in množične literature, prestopanje med med avtorjem in občinstvom, profesionalizmom in amaterizmom ter visoko umetnostjo in popom. S tem je postavil temelje za tipično "ameriško«, "pozitivno" dojemanje postmodernizma, ki je ideološko v diametralnem nasprotju z evropskim, predvsem nemškim pojmovanjem. Hkrati pa Fiedler razpravlja že tudi o "dvojni strukturi« - v enem samem postmodernističnem delu naj bi bili tako priča spoju fikcije in resničnosti -, s čimer odpira široko polje pluralizma različnih jezikov in modelov. Janko Kos, Na poti v postmoderno, Ljubljana, Literarno-umetniško društvo Literatura 1995, str. 87.

Helga de la Motte-Haber, "Postmodernism in Music: Retrospection as Reassessment", v: Contemporary Music Review 12 (1995), št. 1, str. 78 .

Ross Feller, "Resistant Strains of Postmodernism: The Music of Helmut Lachenmann and Brian Ferneyhough", v: Judy Lochhead in Joseph Auner (ur.), Postmodern Music/Postmodern Thought, New York in London, Routledge 2002, str. 250.

8 Nikolai Kompridis, "Learning from Architecture: Music in Aftermath to Postmodernism», v: Perspectives of New Music 31 (1993), št. 2 , str. 7. 
Najdlje je šel v takem relacijskem pojmovanju postmodernizma Hermann Danuser, ki je prav zaradi različnega pojmovanja modernizma izpeljal dve različni definiciji postmodernizma. ${ }^{9}$

Relacijskosti postmodernizma pa ne otežuje samo narava njegove zveze z modernizmom, temveč že sam pojem modernizma, zato je smiselno jasno razločevanje med pojmi »modernost«, "moderna" in »modernizem«: modernost je predvsem ideološkofilozofska drža, za katero je značilno dojemanje pomembnosti inovacije in linearnega Življenjskega časa, človekove emancipacije in racionalnosti, moderna je zgodovinska epoha, v kateri se udejani in vlada ideološka modernost, modernizem pa je umetniška smer $v$ obdobju moderne, v kateri so ideje modernosti izživete do svojih skrajnosti, kar pripelje do končnega preloma z obdobjem moderne.

$\mathrm{V}$ kolikor postmodernizem razumemo kot enega izmed slogovnih tokov v 20. stoletja, potem je mogoče trditi, da se njegova relacijskost veže na modernizem in ne na modernost ali moderno. Razmerje med postmodernizmom in modernizmom pa seveda določa predpona »post«. Prefiks je mogoče razumeti tako časovno kot vsebinsko. Časovni odnos se razkriva kot neproblematičen - "post kaže na časovno poznejšost, naknadnost, nasledstvo. ${ }^{10}$ Veliko več težav predstavlja predpona "post « na vsebinski ravni razumevanja. Med mnogimi možnostmi velja izpostaviti tiste tri, ki se v razpravah o postmodernizmu ponavljajo najpogosteje. Tako naj bi predpona "post«v relaciji do modernizma pomenila:

a) nadaljevanje in radikalizacijo modernizma,

b) reakcijo na modernizem in njegovo abruptno prekinitev,

c) začetek povsem novega obdobja oziroma sloga.

Največ avtorjev izpostavlja prvo možnost (a). Tako opozarjata na tesno navezanost postmodernizma na modernizem Janko Kos in Tomo Virk - v postmodernizmu naj bi šlo samo še za radikalizacijo v modernizmu sproženega metafizičnega nihilizma. ${ }^{11}$ Podobno je bil prepričan že eden izmed najzgodnejših teoretikov arhitekturnega postmodernizma Charles Jencks, ki je poudarjal, da postmodernistična arhitektura raste iz modernistične, ${ }^{12}$ da torej ne uveljavlja »revolucionarne» prakse in tako samo nadaljuje modernistično tradicijo, ki pa jo hkrati že tudi presega. ${ }^{13}$ Med muzikološkimi avtorji razume postmodernizem kot posledico modernizma Wilfried Gruhn, ${ }^{14}$ navezanost postmodernizma na modernizem pa izpostavlja tudi Thomas Schäfer razmerje med postmodernizemom in modernizmom zanj ni opozicijsko, temveč dialektično. ${ }^{15}$ Pojem dialektičnosti je razbrati tudi iz spisov Hermanna Danuserja, ki

9 Prim.: Hermann Danuser, "Zur Kritik der musikalischen Postmoderne«, v: Quo vadis musica?, ur. Detlef Gojowy, Kassel, Bärenreiter 1990, str. 82 .

10 Tak tip časovne relacije $\mathrm{v}$ bistvu potrjuje tudi Umberto Eco, ki sicer sodi med tiste redke raziskovalce, ki postmodernizem razumejo izrazito ahistorično: tako naj bi bilo mogoče najti v zadnji, sklepni, pozni fazi vsakega zgodovinskega obdobja tudi njegovo "postmodernistično« fazo, v kateri osrednje značilnosti obdobja prerastejo v manieristično šablono brez prave vrednosti. Tudi Eco pa s svojim postmodernizmom poudarja nasledstvenost in poznejšo fazo (Umberto Eco, Ime rože, Ljubljana, Mladinska knjiga 1984).

Prim.: Tomo Virk, Strah pred naivnostjo. Poetika postmodernistične proze, Ljubljana, Literatura 2000, str. 38.

Prim.: Charles Jencks, Jezik postmoderne arhitekture, Vuk Karadžić, Beograd 1985.

Prim.: Aleš Erjavec, Estetika in kritična teorija, Ljubljana, Znanstveno in publicistično središče 1995.

Prim.: Wilfried Gruhn, „Postmoderne Musik oder Von neuem Wein in alten Schläuchen uned der Lampe des Diogenes«, v: Isti (ur.), Das Projekt Moderne und die Postmoderne, Regensburg, Gustav Bosse Verlag 1989, str. 5-13.

15 Thomas Schäfer, "Anti-Moderne oder Avantgarde-Konzept? Überlegungen zur musikalischen Postmoderne", v: International Review of the Aesthetics and Sociology of Music 26 (1995), št. 2, str. 224. 
postmodernizma prav tako ne razume kot preproste negacije modernizma, temveč vidi med obema obdobjema značilno dialektično razmerje. ${ }^{16}$ Zelu blizu takemu pojmovanju je tudi Björn Heile, ki isto razmerje obravnava kot dialoško, zato med obema slogoma ne odkriva direktnega antagonizma, kar otežuje jasno kronološko razmejitev. ${ }^{17}$ Heile postmodernizem razume kot "protipodobo modernizma, ki vključuje vse, kar je modernizem izključil. ${ }^{18} \mathrm{~V}$ vrsto zgornjih avtorjev pa se vključuje tudi Wolfgang Welsch, za katerega postmoderna ${ }^{19}$ nadaljuje izročilo moderne - osrednje inovacije moderne naj bi bile $\mathrm{v}$ postmoderni šele prvič dobro vnovčene in izpeljane. ${ }^{20}$ Vse, kar je moderna preizkušala specialistično - ezoterično -, naj bi postmoderna realizirala v vsej širini - eksoterično. ${ }^{21}$ Po Welschu je postmoderna pravzaprav radikalna moderna, ki pa zapušča modernistične ideje stalne inovacije, napredka, enotnosti in totalnosti.

Drugo varianto, po kateri gre postmodernizem razumeti kot reakcijo na modernizem in s tem tudi njegovo zavrnitev (b), je mogoče povezovati s t.i. »časnikarskim» postmodernizmom. Gre za značilno pojmovanje, kakršno se je naselilo predvsem v »lahkotnejšem« revialnem tisku, ki je pozdravil najnovejša dela. Ta naj bi se namreč znebila modernističnega hermetizma in tako spet omogočala dejavno komunikacijo z občinstvom. V središču tako pojmovanega postmodernizma naj bi se zopet znašlo "srce« in njegova iracionalnost, ki naj preglasi racionalne modernistične konstrukte, poljubnost takšnega časnikarskega postmodernizma pa v resnici ni prava pluralnost - za Welscha osrednja značilnost postmoderne -, temveč le nekakšna potpurijska oblika, ki sicer omogoča poudarjeno komunikativnost, po drugi strani pa zapira vsakršno možnost refleksije. ${ }^{22} \mathrm{~V}$ Welschevem duhu se proti takšnemu »časnikarskemu« postmodernizmu, ki izrašča iz negativne nastrojenosti do modernizma in ga je zato mogoče razumeti kot antimodernizem, obrača tudi T. Schäfer. Po njem naj bi šlo zgolj za novo fasado v obliki kulturne zamrznitve, v resnici pa »[p] ostmoderna nima veliko skupnega z zgolj iracionalno-eklektično estetiko, z novim historičnim realizmom, tradicionalizmom ali subjektivizmom. «23

Tako nam ostane še možnost, po kateri bi postmodernizem predstavljal povsem nov slog (c), vendar pa je takšno razumevanje predpone "post« zavito v lastno protislovje. Vodilni italijanski filozofski teoretik postmodernizma Gianni Vattimo namreč opozarja, da je dojemanje postmodernizma kot novega obdobja nemogoče oziroma vsaj paradoksno, ker v svoje bistvo vključuje možnost preseganja, razvojnega loka napredka, ki pa naj bi se prav v postmodernizmu izgubil. ${ }^{24}$ Če naj bi bilo za obdobje

16 Hermann Danuser, »Musikalische Zitat- und Collageverfahren in Lichte der (Post)Moderne- Diskussion", v: Bayerische Akademie der Schönen Künste: Jahrbuch 4 (1990), str. 397.

17 Björn Heile, „Collage vs. Compositional Control: The Interdependency of Modernist and Postmodernist Approaches in the Work of Mauricio Kagel«, v: Judy Lochhead in Joseph Auner (ur.), Postmodern Music/ Postmodern Thought, New York in London, Routledge 2002, str. 288.

18 Prav tam, str. 287.

19 Welsch uporablja v skladu z nemško tradicijo to izpeljanko in ne pojma postmodernizem.

Wolfgang Welsch, Unsere postmoderne Moderne, Weinheim, VCH 31991, str. 185.

Prav tam, str. 83.

Prav tam, str. 81.

T. Schäfer, nav. delo, str. 221.

Gianni Vattimo, Konec moderne, Ljubljana, Literatura 1997, str. 10. 
postmodernizma značilno prav preseganje ideje napredka in konstantne inovacije, potem postmodernizem sam ne more biti radikalno nov in inovativen.

Zgornje dileme o naravi relacijskega razmerja med modernizmom in postmodernizmom oziroma o modusu odvisnosti postmodernizma od modernizma želim v nadaljevanju prikazati na zgledu kompozicije Tallis. Odsevi za veliki orkester Petra Ruzicke.

Ruzicka se je rodil leta 1948, torej le malo pred tem, ko so bili v Darmstadtu predstavljeni največji prelomi (leta 1951 Boulezov serializem in Cageovo naključje), zato ga lahko postavljamo v drugo povojno generacijo. Pomenljivo je tudi to, da je s študijem pričel leta 1968, torej v času prelomnih študentskih revoltov in praške pomladi, glede na prevratna povojna leta pa je bila odločilno spremenjena tudi slogovna situacija, saj je napočil čas modernističnih sintez (zvočne kompozicije skladateljev poljske šole in G. Ligetija). Vendar pa je zorenje Ruzicke potekalo precej neodvisno tudi od tega konteksa, kar gre povezovati z dvema skladateljevima osrednjima specifikama: študiral ni samo glasbe, kot skladatelj pa je vedno ostal avtodidakt.

Ruzicka je tako študiral pravo, organizacijske vede, muzikologijo in teatrologijo. Leta 1977 je celo doktoriral iz prava, nikoli pa ni institucionalno študiral kompozicije. Sam skladatelj je potrebo po tako široki izobrazbi utemeljil z mislijo, da se mu zdi v sodobni družbi kot skladatelju zelo nevarno posedovati zgolj glasbeno-obrtna znanja, zato se je odločil še za pravo, ki je nekakšna socialna disciplina v najširšem pomenu te besede. ${ }^{25}$ Podobno raznolike kot študij so bile tudi zaposlitve Ruzicke (bil je intendant Nemškega simfoničnega orkestra iz Berlina, intendant Hamburške državne opere, umetniški svetovalec orkestra Concertgebouw, vodja Münchenskega bienala, vodja Salzburškega poletnega festivala in profesor za kulturni menedžment na Visoki šoli za glasbo v Hamburgu, ukvarjal se je z zakoni o avtorskih pravicah, deloval kot redaktor pri glasbeni založbi, dirigent ipd.), ${ }^{26}$ zato je mogoče odkriti druženje različnih »svetov« že na ravni skladateljeve študijske in življenjske poti.

Značilna razpetost pa je morda tudi posledica skladateljevega samouštva. Tako ne moremo mimo spoznanja, da je Ruzicka pogosto menjal svojo poetiko, medtem ko je njegova estetika ostajala večinoma nespremenjena in povezana z močno refleksijo o glasbi. Ustvarjanje tako pred Ruzicko ne postavlja zgolj obrtniških vprašanj, temveč prave eksistencialne dileme.

Kot edinega kompozicijskega učitelja Ruzicke lahko štejemo H. W. Henzeja Ruzicka je torej iskal znanje pri v tistem času značilno osamljenem in tradicionalističnem skladatelju, vendar pa se je med letoma 1967 in 1970 otresel učiteljevega zgleda. ${ }^{27}$ Zavezal se je t.i. »kritični kompoziciji«, prek katere je razkrival dialektiko v pogojih glasbene recepcije in produkcije (skladbo Emanazione za flavto in orkester iz leta 1975 je tako mogoče razumeti kot razpravo o virtuoznosti kot ekstremni utelesitvi

\footnotetext{
25 Hanspeter Krellmann: „Komposition als Moment der Verweigerung. Gespräch mit dem Komponisten Peter Ruzicka«, v: Musica 30 (1976), št. 2, str. 122.

26 Uwe Sommer, »Peter Ruzicka«, v: Komponisten der Gegenwart, Hanns-Werner Heister in Walter- Wolfgang Sparrer (ur.), München, Edition Text + Kritik 1992, str. 2.

27 Prav tam, str. 3.
} 
emocionalnega izraza in hkrati zgolj navidezni, površniski pozi), ${ }^{28}$ kar lahko povezujemo s skladateljevimi izkušnjami iz glasbenega menedžmenta. Tak tip glasbe je seveda zelo ozko povezan z razmišljanjem o glasbi - ne samo o njenem kompozicijskem ustroju, temveč o njeni širši vpetosti v kulturo in funkcioniranje družbe nasploh. Zvočnost teh del je trša, eskperimentalna, anarhična, a tudi bolj energična.

Z zelo poudarjeno refleksijo o glasbi pa je povezana tudi naslednja stopnja razvoja glasbenega jezika Ruzicke. V drugi polovici sedemdesetih let je sprejel še radikalnejšo modernistično poetiko, zato se vsako njegovo delo razkriva kot poudarjeno zanikanje starega in iskanje povsem novega, še neznanega glasbenega materiala. To stopnjo je sam skladatelj po Adornovem izrazu poimenoval kot "musica negativa« - kompozicija postane tako v resnici dekompozicija. ${ }^{29}$ Osrednje značilnosti takšnega glasbenega stavka so povezane s tišino, molkom, prelomom, zlomom in fragmentarno strukturo, o čemer govorijo tudi nekateri naslovi del: Torso, Abbrüche, ...über ein Verschwinden, Gestalt und Abbruch. Tako konsekventno iskanje novih izrazil in še bolj materiala je Ruzicko konec sedemdesetih let (1979-81) vodilo v kompozicijsko krizo in ustvarjalni molk. Skladatelj je namreč spoznal, da ni več mogoče napisati ničesar resnično novega. Zavedal se je, da je »objektivno [...] nemogoče nadaljevati dinamiko evolucije materiala, ki je bila odločilna v preteklih desetletjih «. ${ }^{30}$ Skladateljevo zaupanje v razvojno moč glasbe je postalo močno omajano: "Zgodovina glasbe dveh dekad po vojni je zaznamovana s konstantnim vpeljevanjem novega, 'neslišanega' materiala. Danes, na začetku sedemdesetih let se je ta proces eksplozije materiala, ta inherentna revolucionarnost Nove glasbe prvič ustavila. Če izhajamo iz tega, da naj danes komponirana glasba ne zadostuje le sama sebi, da naj bi imela svojo lastno kritično ost, potem potrebuje predvsem premislek o prav tej specifični zgodovinski situaciji. 31 $^{1}$

Izhod iz skladateljske krize je Ruzicka našel s pomočjo novega koncepta, ki je zopet tesno povezan z refleksijo o glasbi sami. Ruzicka piše tako po letu 1980 glasbo o glasbi, ki se mu zdi »edina preostala možna posledica umetnostno-zgodovinskega razvoja, ki stoji pred priznanjem, da resnično nov glasbeni material ni več na razpolago, da

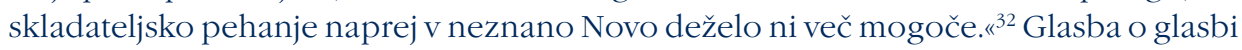
je komponirana na podlagi in s pomočjo že obstoječega glasbenega dela, zato je Ruzickova tehnika izredno podobna renesančnemu parodiranju. ${ }^{33}$ Skladatelj se ne distancira več od tradicije, temveč se nanjo celo namerno nanaša - v trenutku, ko ni na razpolago več noben nov material, je mogoče uporabljati tudi starega. Vendar pa ne gre za golo izrabljanje starih izrazil, temveč za poudarjeno refleksivnost glasbe. Citati, aluzije in parafraze že znane, "pretekle« glasbe pridobivajo v novem kontekstu - večkrat značilno modernistični teksturi - povsem nove pomene. Komponiranje s citati postaja tako bolj kot ne komponiranje s semantičnimi potenciali različnih kontekstov: »Citati in aluzije so v večini primerov prevzeli funkcijo reference, kar pomeni,

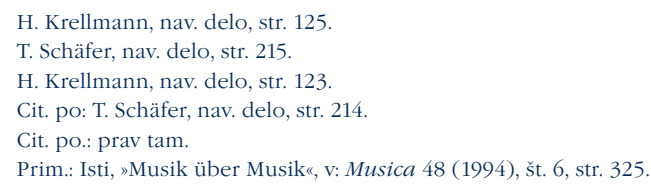


da Ruzicka s citiranim predtekstom hkrati na produktiven način izkorišča tudi njegovo semantično polje. «34 Pomembno je torej spoznanje, da nanašanje na zgodovinski predtekst ne prinaša le že znanega materiala, temveč dobiva v delu karakter znaka takšno navezovanje na že obstoječo glasbo preteklosti prinaša najrazličnejše konotacije, ki ustvarjajo močno povednost. Gre za nekakšen »asociativni kontrapunkt « ${ }^{35}$ med novim in starim tekstom, zato bi lahko govorili celo o značilnem intertekstualnem postopku.

Ruzicka se v delih, ki jih je mogoče postaviti v kontekst pisanja glasbe o glasbi, navezuje na zelo različne skladateljske tradicije (v orkestrski skladbi Annäherung und Stille predstavlja izhodiščni material fragment Schumannovega nedokončenega Klavirskega koncerta $v$ d-molu, Metamorphosen über ein Klangfeld von Joseph Haydn se razvijejo v niz obdelav ene same harmonske sekvence iz Haydnove kantate Sedem poslednjih besed našega Odrešenika na križu, v delu ...das Gesegnete, das Verflüchte... pa skladatelj izkorišča fragmentarne ostanke 17. simfonije, ki jih je našel v zapuščini švedskega skladatelja Allana Petterssona), čeprav ni mogoče prezreti, da stopa največkrat v aktiven dialog z glasbo Gustava Mahlerja - »...fragment..."za godalni kvartet se tako izvije v citat iz Mahlerjevega Adagia iz Desete simfonije, glasba za violo in orkester »...den Impuls zum Weitersprechen erst empfinge "kroži okoli izsekov iz skladateljeve Devete simfonije, kratka misel iz iste simfonije pa se je prikradla tudi v Tretji godalni kvartet $\mathrm{z}$ naslovom ...über ein Verschwinden. Da je prav Mahlerjeva ustvarjalnost tista »arhimedova točka«, ${ }^{36}$ okoli katere kroži Ruzickov opus, pa nenazadnje dokazuje tudi dejstvo, da je prav Ruzicka redigiral in izdal prvi stavek Mahlerjevega fragmentarno ohranjenega Klavirskega kvarteta.

Tipičen primer glasbe o glasbi predstavlja tudi orkestrsko delo Tallis. Odsevi za veliki orkester iz leta 1993. Veliko nam pove že naslov skladbe - Ruzicka namreč glasbeno »razmišlja« o Tallisovem štiridesetglasnem motetu Spem in alium, za katerega se zdi, da tu in tam kot odsev pogleda skozi modernistično teksturo Ruzickove partiture. Takšno približevanje in oddaljevanje od izhodiščnega Tallisovega dela bi lahko razumeli tudi v smislu palimpsesta - skozi porozno modernistično plast proseva na določenih mestih bolj in na drugih spet manj očitno Tallisova renesančna polifonija. Priča smo torej značilnemu druženju dveh svetov: modernističnega in nemodernističnega (Tallisovega), vendar pa takšno sopostavljanje ne poteka le na ravni enostavne konfronatacije različnega. Ob natančnejšem opazovanju partiture dela namreč lahko ugotovimo, da se je Tallisov motet zažrl veliko globlje v strukturo celotne kompozicije in da tako v veliki meri določa celo skladbo in ne zgolj nekaterih izoliranih mest.

Skladba Tallis je napisana kot v enem dihu, vendar se po podrobnejši analizi vendarle izkaže, da jo sestavljajo dva dela in zaključna koda z vmesnimi prehodi, ki skupaj rišejo tipični lok od mirnega k razboritemu in povratku nazaj v umirjeno (gl. prim. 1).

\footnotetext{
Isti, „'Verschwiegene Lieder' - ein instrumentales ‘Requiem’ für Paul Celan«, v: Die Musikforschung 50 (1997), št. 3, str. 295. Isti, »Musik über Musik«, str. 326.

Wulf Konold, "Peter Ruzicka«, v: Peter Ruzicka, Deutscher Musikrat. Edition zeitgenössische Musik, Mainz, Wergo 1993.
} 


\begin{tabular}{|c|c|c|c|c|}
\hline 1. del & Prehod & 2. del & prehod & koda \\
\hline takt 1-106 & takt 107-132 & takt 133-169 & takt 170-189 & takt $190-238$ \\
\hline $\begin{array}{l}\text { I, }{ }^{37} \text { II, III, IV, V, } \\
\text { XXIII, parafraza } \\
\text { Tallisa (a), VII, VI, } \\
\text { parafraza Tallisa } \\
\text { (b), VIII, X, IX, } \\
\text { parafraza Tallisa } \\
\text { (c), citat Tallisa } \\
\text { (d), XI, parafraza } \\
\text { Tallisa (e), dva } \\
\text { štiridesetglasna } \\
\text { nastopa Tallisa } \\
\text { (f,g) }\end{array}$ & $\begin{array}{l}\text { XII, XIII, XIV, XV, } \\
\text { XVI, XVII, XVIII + } \\
\text { VI, X, XI }\end{array}$ & $\begin{array}{l}\text { XIX, XX, trikrat } \\
\text { inverzija para- } \\
\text { fraze Tallisa } \\
(\mathrm{h}-\mathrm{j})+\mathrm{V}\end{array}$ & XXI + XIX, XX & $\begin{array}{l}\text { XXIII, sozvočje } e-a \text {, } \\
\text { osrediščenost okoli } \\
\text { tona } e\end{array}$ \\
\hline
\end{tabular}

Primer 1. Formalna shema Ruzickove skladbe Tallis.

Formalna enovitost dela izhaja iz krožne napetostne strukture, ki se ob koncu vrača v svoje izhodišče, strukturalna enotnost pa je posledica Ruzickovega značilnega obravnavanja materiala. Celotna skladba je namreč sestavljana iz drobnih materialnih okruškov, ki se ponavljajo in vpenjajo v širši kontekst, med njih pa so vstavljene še bolj ali manj odprte aluzije na Tallisov motet. Odkrijemo lahko vsaj štiriindvajset takih enot - drobcev - (gl. prim. 2), za katere pa se ob nadrobnejšem opazovanju izkaže, da so med seboj povezane. Očitno namreč postane, da so izpeljane druga iz druge in da tako tvorijo gosto tematsko mrežo, katere osnovni nosilci so štirje glavni materialni drobci:

- interval kvinte oz. sozvočje »prazne kvinte« (najbolj jasno ga je ugledati v »drobcu« II);

- poudarjene repeticije (zaznamujejo vrsto drobcev);

- interval in sozvočje velike oz. male terce (prvič nastopi na začetku prehoda v drugi del kot drobec XII) ter

- postop male oziroma velike sekunde (osnovo predstavlja drobec XIV).

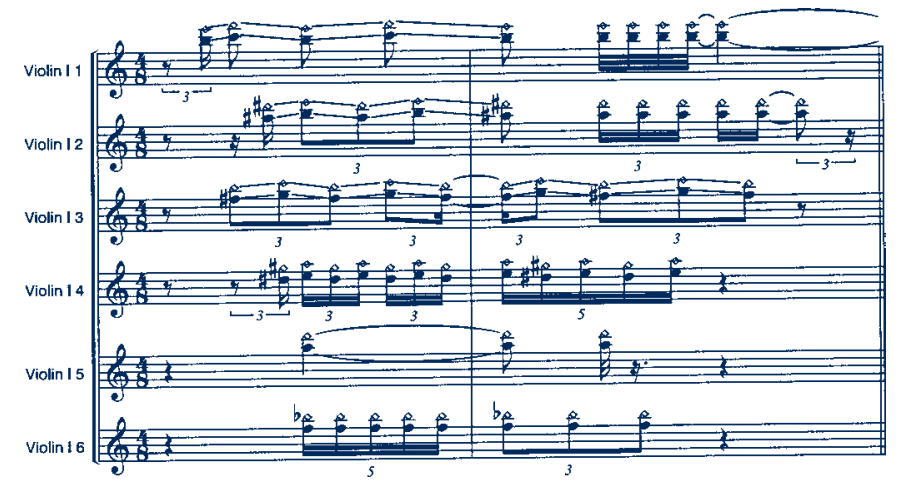

\section{I}

Zadnja vrstica tabele kaže distribucijo materiala. Rimske številke označujejo materialne drobce - gl. prim. 2, črke pa aluzije na Tallisov motet - gl. prim. 5 . 
G. POMPE • PALIMPSESTNA STRUKTURA SKLADBE TALLIS ... $\frac{1}{2-1}$

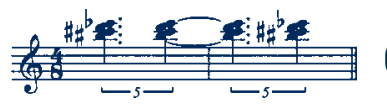

III

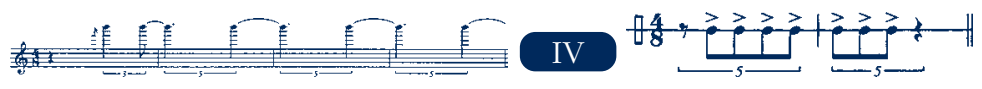

$\mathrm{V}$

\&XIII

VII

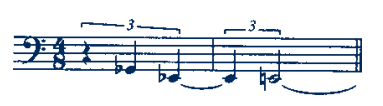

VI

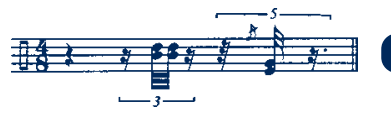

VIII
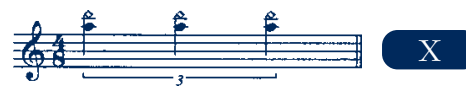

I.
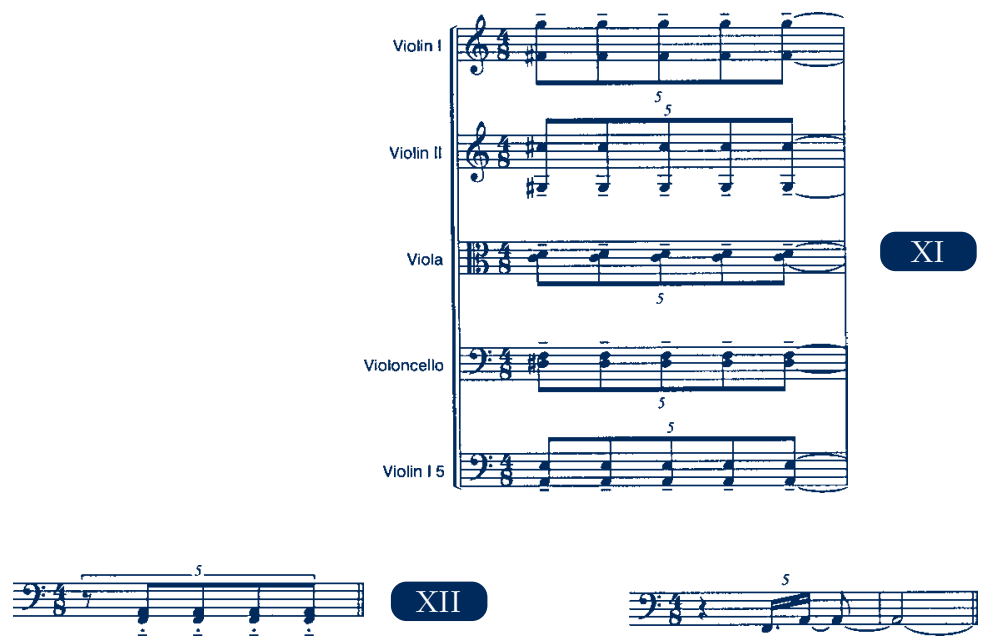

XII

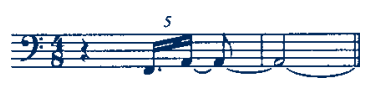

XIII

$\stackrel{X I V}{2}$

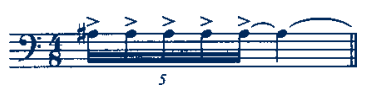

$\mathrm{XV}$

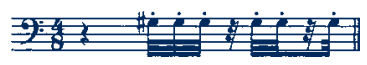

XVI

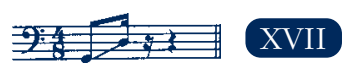

XVIII 
MUZIKOLOŠKI ZBORNIK • MUSICOLOGICAL ANNUAL XLII/1

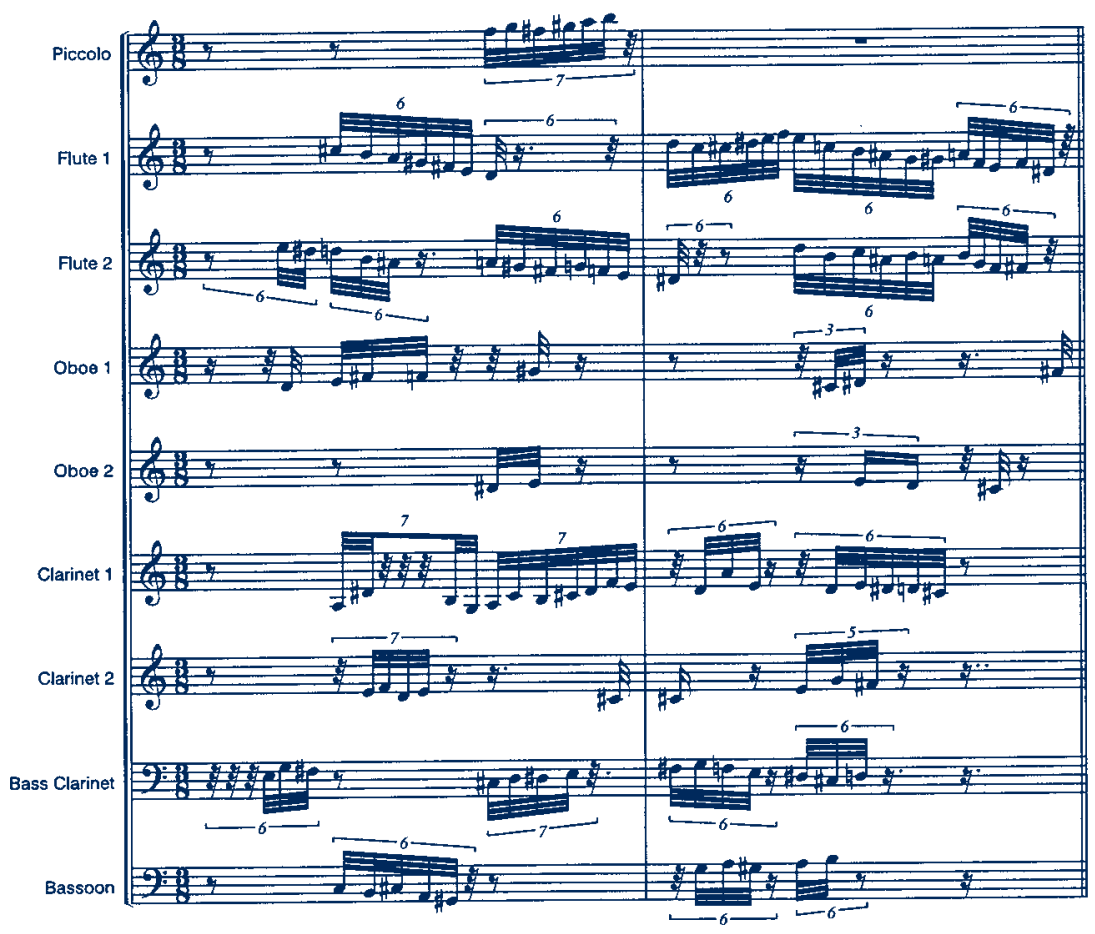

XIX

ležeči ton ali prazna kvinta $\rightarrow \mathrm{XX}$

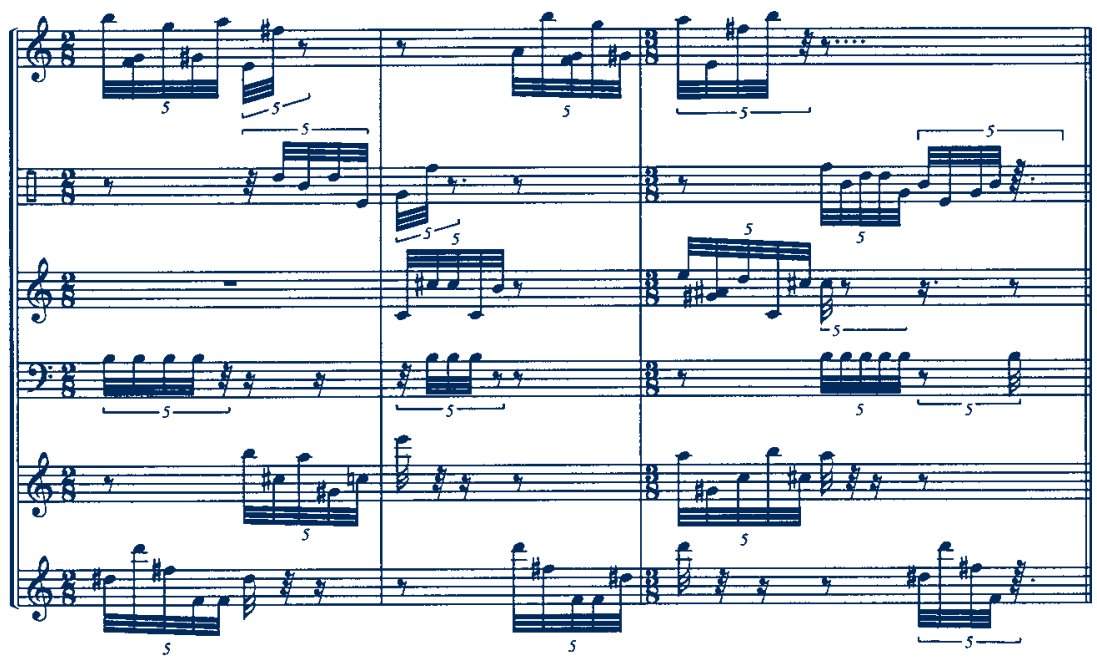

XXI 

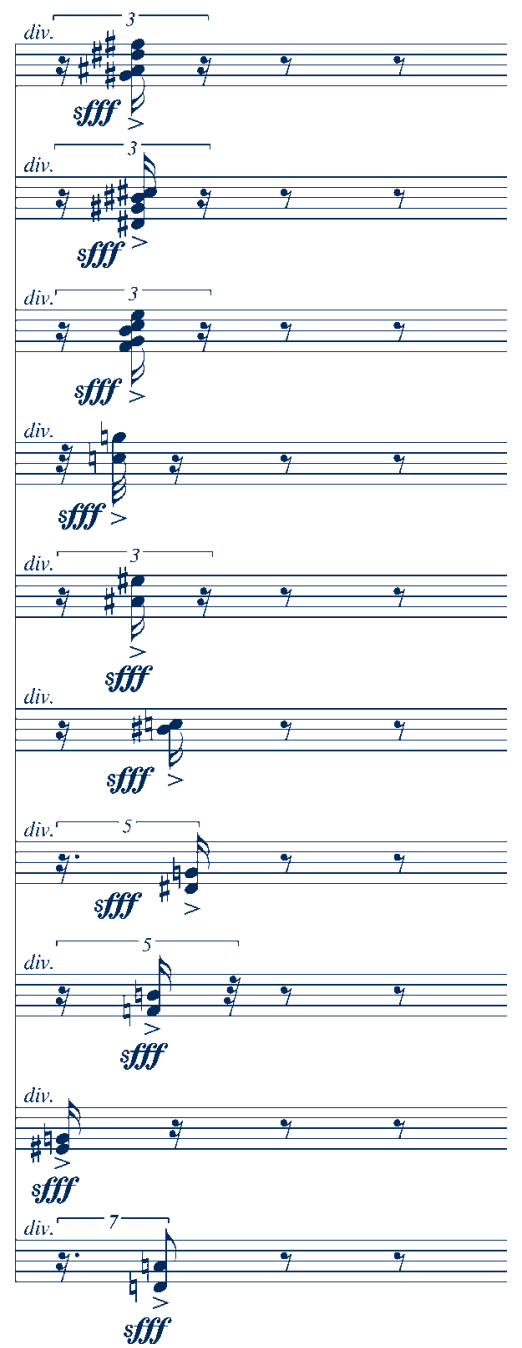

Primer 2. Osnouni materialni drobci za Ruzickovo delo Tallis (I-XXIII) glede na vrstni red nastopa.

Iz osnovne ideje sozvočja prazne kvinte (II) so tako izpeljani še - gl. prim. 3 drobci XVIII, XVII in XX. Iz osnovnih repeticij (XXIII) je razvito največ drobcev, in sicer X, ki s svojimi flažoleti že predstavlja osnovo za I, nato pa še XI, IV, V, III, drobec XV prinaša diminuirane repeticije, ki so v drobcu XVI kombinirane še s pavzami, kar pripelje skupaj z mnogimi menjalnimi notami že do močno »oddaljenih « drobcev XIX, XXI ter VII in VIII (repetirajoči ritmični utrip z razprtimi tonskimi višinami). Drobec XII predstavlja osnovo za drobca XIII (sozvočje velike terce je zamenjano s skokom 
velike terce) in VI (namesto skoka velike terce navzgor, imamo malo terco navzdol), medtem ko iz drobca XIV izhaja drobec IX (ta je deloma povezan tudi z idejo repeticije).

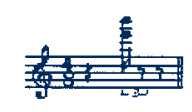

II

(prazna kvinta)

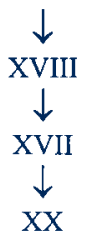

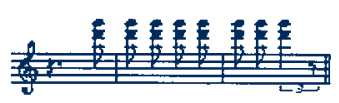

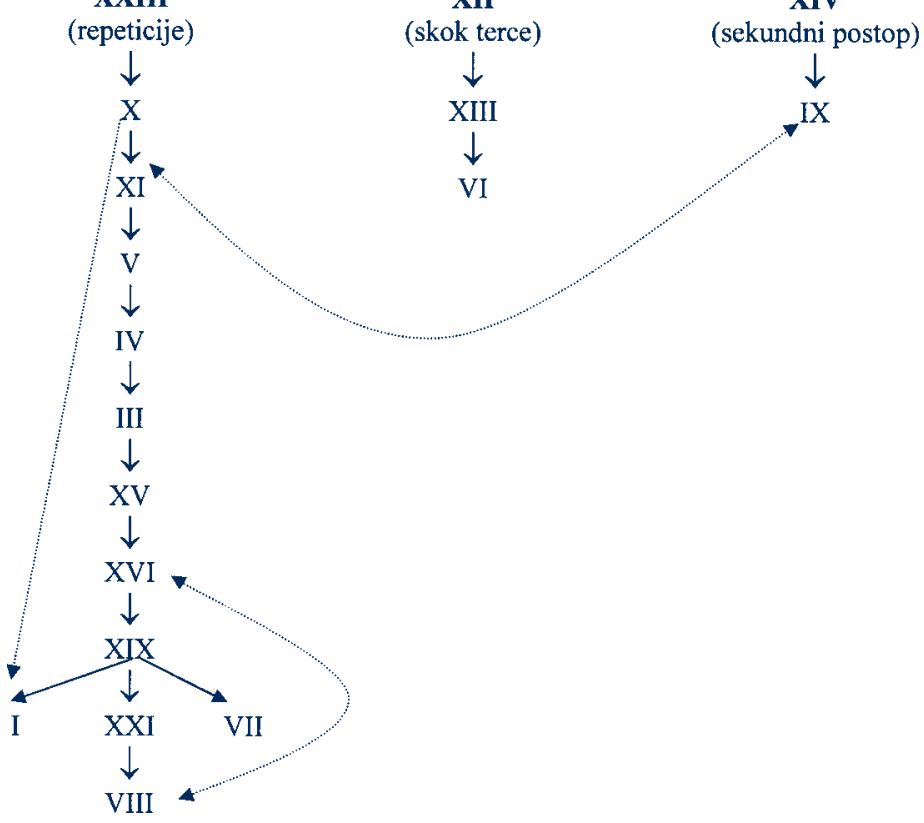

XXIII

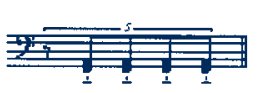

XII
(skok terce)

.




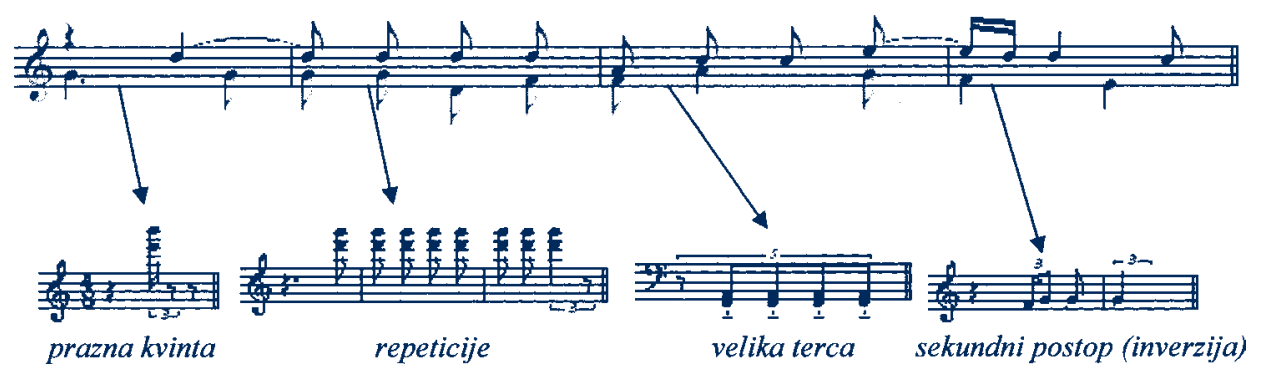

Primer 4. Izpeljava glavnih materialnih drobcev iz začetka Tallisove skladbe Spem in alium.

»Vdor« Tallisa v Ruzickovo istoimensko skladbo poteka torej na več ravneh: (1) v obliki semantično poudarjenih aluzij in citatov, (2) v materialni povezanosti ponavljajočih se drobcev z začetkom Tallisove skladbe in (3) celo na ravni oblikovanja teksture - podobno kot v Tallisovem motetu tudi umirjenost Ruzickovega dela prebijajo abruptni izbruhi. ${ }^{38}$ "TALLIS je parodija in hkrati ni parodija ${ }^{39}$ - reminiscence na Tallisovo skladbo so vseskozi prisotne, a nastopajo enkrat v obliki jasnega citata, drugič v obliki aluziji in tretjič kot popolnoma modificirane parafraze. V tej zadnji fazi so spremenjene oz. "potujene« do te mere, da jih ni več mogoče dobro ločiti od tipično modernističnega glasbenega stavka (flažoleti, clustri, poliritmika ipd.) in v tem je posebnost Ruzickovega palimpsesta: obe zgodovinsko povsem različni plasti (v našem primeru tudi slogovna) sta se na mnogih mestih zlili druga v drugo, s čimer sta odprli možnost za široko semantično polje, za refleksijo tako o sodobnem stanju glasbenega materiala kot tudi o odnosu do davno pretekle glasbene tradicije.

In prav v tej sopostavitvi in delni zlitosti različnih slogovnih plasti lahko ugledamo odgovor na naše začetno vprašanje o odvisnosti postmodernizma od modernizma. Gosta mreža povezav med materialnimi drobci, njihova izpeljava iz Tallisovega moteta in premišljena formalna gradnja, ki poteka brez abruptnih prelomov v enemem samem napetostnem loku izkazujejo organsko povezan, homogen glasbeni stavek, ki poteka v znamenju racionalne premišljenosti, urejene kristalne strukture in homogenosti, kar so vse pomembne modernistične značilnosti. Te pravzaprav prevladujejo, čeprav se zde v nenavadnem neskladju s površino skladbe, na kateri lahko v recepcijskem aktu zasledujemu navidez heterogeno palimpsestno igro približevanja in oddaljevanje od Tallisovega moteta. Istočasna homogenost (izpeljevanje iz skupnega jedra, enovit napetostni lok) in heterogenost (modernistične tehnike vs. »vdori« renesanančne polifonije) pričata o sopostavljanju dveh svetov-modernističnega in nemodernističnega -, ki sta vpeta v refleksijo o glasbi sami, kar moramo znova spoznati kot osrednjo značilnosti postmodernistične glasbe. 
MUZIKOLOŠKI ZBORNIK • MUSICOLOGICAL ANNUAL XLII/1
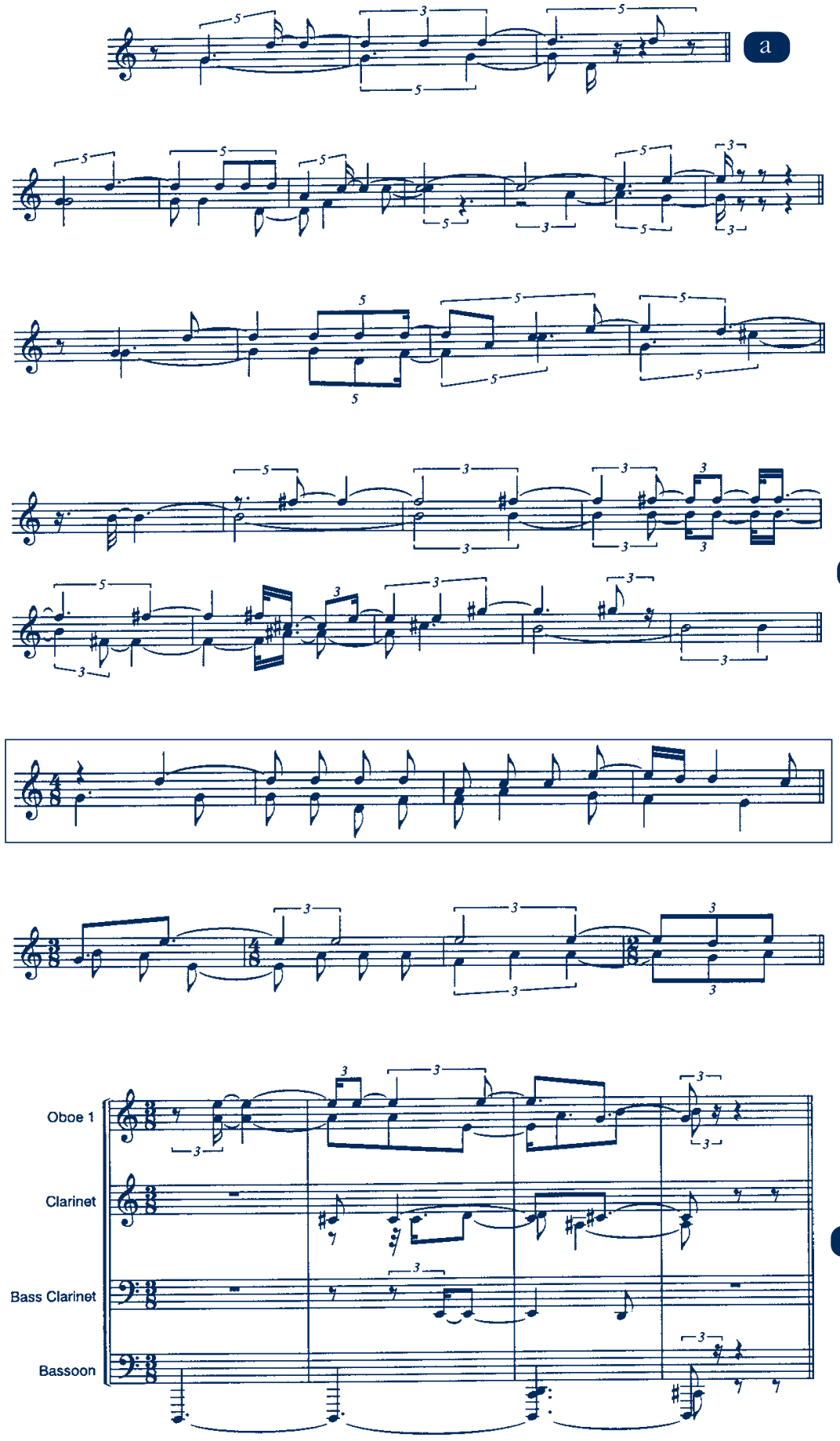


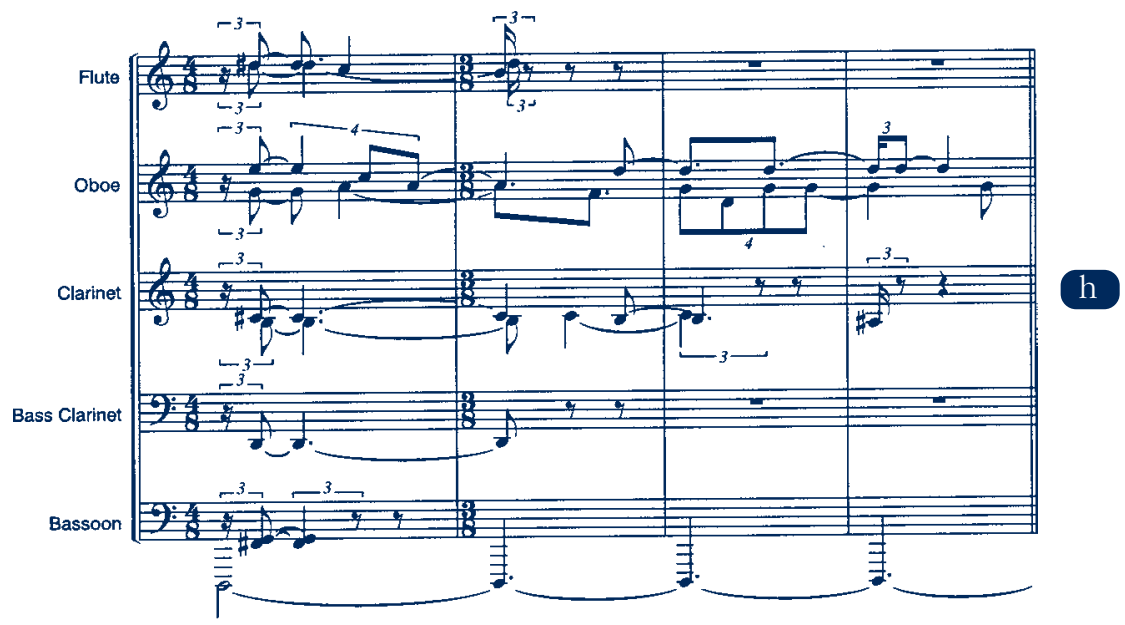

Primer 5. Postopno oddaljevanje parafraz od zgleda.

Skladba Tallis se nam tako razkriva kot tipično postmodernistično delo, v katerem smo priča združevanju dveh različnih svetov. Prevladujočega modernističnega lahko ugledamo v harmonskih clustrih, poliritmiki, gosti nemelodični teksturi, ritmični kompleksnosti in formalni enovitosti, ki raste iz racionalno premišljene strukture, tega pa na določenih mestih prebija nemodernistična plast, ki jo prinašajo aluzijski drobci in celo dobesedni citat Tallisovega moteta. Postmodernizem se kaže prav v takšnem druženju in njegovem povednem potencialu: nemodernistični »otočki« pridobijo znotraj modernističnega konteksta izstopajoče mesto in tako tudi asociacijsko semantično vrednost.

Kot je pokazala analiza, je prevladujoči modernistični »ocean« (tak najbolj tipični primer predstavljajo na primer uvodni glissandirajoči poltonski flažoleti v visokem registru deljenih godal) izpeljan iz Tallisovega gradiva, ki ga je mogoče razumeti kot osnovno materialno jedro. Seveda pa je ta material prek mnogih postopkov mestoma modificiran do te mere, da ga je nemogoče povezati s kontekstom renesančne polifonije in se zdi celo tipično modernističen. Posamezne aluzije (a-j; prim. 5) na Tallisovo glasbo so podobno kot iz njih izpeljani materialni drobci ujete v mrežo povezav: bližnjih in bolj oddaljenih (gl. prim. 5 - od parafraze a, b, c in e raste podobnost, nato pa smo od j do i in h spet priča oddaljevanju), zato se postavlja vprašanje - gl. prim. 5 -, kje iskati jasno mejo med modernističnim in nemodernističnim v procesu palimpsestnega oddaljevanje od prvotne plasti, od »izvirnika«. Prav ta izmuzljivost najbolj razkriva odnosno zvezo med modernizmom in postmodernizmom - slednji iz njega izhaja, uporablja njegove tehnike, a jih mestoma prebija z vdori nemodernističnih "otokov«, ki sprožajo poudarjeno semantiko, kar se zdi nasploh osrednja postmodernistična značilnost. Brez jasne zavezanosti modernizmu, ki ponavadi opravlja vlogo prevladujočega zvočnega konteksta, semantika postmodernistične skladbe v resnici ni postmodernistična, temveč je zavezana manierističnemu slogovnem kopiranju, zaradi česar bi ob mnogih sodobnih skladateljskih imenih lažje zapisali, da so 
neoromantiki, neoimpresionisti ali neoklasicisti kot postmodernisti - semantika njihove glasbe ne izhaja iz druženja raznolikih svetov (modernističnega in nemodernističnega), temveč iz značilnosti prevzetega slogovnega modela (npr. romantičnega, impresionističnega, klasicističnega). Odvisnost postmodernizma od modernizma je torej ključna.

\section{SUMMARY}

Attempts to define postmodernism as a stylistic period have turned out to be facing dilemmas that originate in the linguistic construction of the very concept: in its core ("modernism") and its prefix ("post«). On the level of content, the prefix "post» renders a number of diverse interpretations possible: it may denote a continuation and radicalization of modernism, a reaction against modernism as well as its abrupt end, or the beginning of a completely new period or rather style. The article attempts to argue for the first variant, which means that postmodernism is neither an antithetical rejection of modernism nor a completely new style. In this way, postmodernism differs clearly from the so-called "journalistic" postmodernism (W. Welsch) that has been more than enthusiastic about the "high \& low genre connection", while, on the other hand, the notion of postmodernism as a new period seems to be also unacceptable, since it includes the possibility of transcending the evolutionary trend of progress (G. Vattimo) that should have, if ever, vanished in postmodernism. The abovementioned relationship between modernism and postmodernism is the case in point to be proven by the example of Peter Ruzicka's symphonic composition Tallis. In the seventies, Ruzicka adopted the stylistic doc- trine of modernism which showed itself in socalled "critical composing" and by which the through musical reception and production conditioned - dialects were brought to light; after which he embraced an even more radical variety of poetics, in keeping with which each and every work was to be considered as an emphatic negation of the old with a view to discovering utterly new, hitherto unknown musical materials. This and such consistent search of new means of expression, and above all of the material, led Ruzicka, towards the end of the seventies, into a compositional crisis and - creative silence. His way out came with the help of the music on music concept, i.e. by composing music on the basis and with the help of an already existing musical work. In this light one can understand the symphonic composition Tallis, which appears to be conceived in a palimpsest manner: allusions to Tallis's motet work their way through a prevailingly modernist texture. The analysis has proven that Ruzicka's compositional procedures are typically modernistic, whereas allusive irruptions of Tallis's music give them a special tinge that represents a contribution to the work's semantic potential, which again seems to be the focal characteristic of postmodernist music. In this light, postmodernist commitment to modernism appears to be of essential importance. 